\title{
Dual-Function Ion Channel/Protein Kinases: Novel Components of Vertebrate Magnesium Regulatory Mechanisms
}

\author{
CARSTEN SCHMITZ, ANNE-LAURE PERRAUD, ANDREA FLEIG, AND \\ ANDREW M. SCHARENBERG
}

\begin{abstract}
Department of Pediatrics [C.S., A.-L.P., A.M.S.], University of Washington and Children's Hospital and Regional Medical Center, Seattle, WA 98195, U.S.A; and Laboratory of Cell and Molecular Signaling [A.F.], Center for Biomedical Research at The Queen's Medical Center and John A. Burns School of Medicine at the University of Hawaii, Honolulu, HI 96813, U.S.A.
\end{abstract} \begin{abstract}
ABST
Although magnesium is the dominant divalent intracellular
cation and is required for the function of diverse types of enzymes that participate in virtually every cellular process, the molecular mechanisms that regulate its homeostasis are poorly understood. Electrophysiologic and biochemical investigations
\end{abstract}

of a novel dual-function ion channel/kinase protein have recently converged with the identification of the gene locus for an autosomal recessive form of inherited hypomagnesemia to provide new insight into vertebrate magnesium regulatory mechanisms.

(Pediatr Res 55: 734-737, 2004)
Magnesium $\left(\mathrm{Mg}^{2+}\right)$ is the dominant divalent intracellular cation, present at several $\mathrm{mM}$ total concentration including $\sim 10$ $\mathrm{mM}$ sequestered in organelles (especially mitochondria), 2-5 $\mathrm{mM}$ in complex with ATP in the cytosol, $0.5 \mathrm{mM}$ as free $\mathrm{Mg}^{2+}$, and trace amounts complexed with enzymes (reviewed in Refs. 1 and 2). $\mathrm{Mg}^{2+}$ 's importance to cell function is underscored by its involvement in the catalytic mechanisms of a tremendous variety of enzymes, including every enzyme that catalyzes a reaction requiring a nucleotide co-factor. Although studies of $\mathrm{Mg}^{2+}$ metabolism in bacterial and yeast strains have allowed the identification of several proteins involved in $\mathrm{Mg}^{2+}$ transport (3-6), only a single homologue of these proteins has been found in humans, and it seems to be a mitochondrial $\mathrm{Mg}^{2+}$ transporter (7). Studies of $\mathrm{Mg}^{2+}$ fluxes of human cells have indicated the presence of one or more plasma membrane $\mathrm{Mg}^{2+}$ active transport mechanisms, but the protein(s) responsible for these fluxes has not been identified $(1,2)$. As a consequence, despite its abundance and biologic importance,

Received September 24, 2002; accepted August 6, 2003.

Correspondence: Andrew M. Scharenberg, MD, Department of Pediatrics, University of Washington and Children's Hospital and Regional Medical Center, 1959 NE Pacific Avenue, Seattle, WA 98195, U.S.A.; e-mail: andrewms@u.washington.edu

Supported by National Institutes of Health grant R01GM64316 to A.M.S. and RO1 GM65360 to A.F.

A.M.S. was the recipient of the Society for Pediatric Research 2002 Young Investigator Award presented at the 2002 Annual Meeting of the Pediatric Academic Societies, Baltimore, MD, U.S.A.

Current affiliation for C.S. and A.-L.P. is Department of Immunology, National Jewish Medical and Research Center, Denver, CO 80206, U.S.A.

DOI: 10.1203/01.PDR.0000117848.37520.A2 the molecular mechanisms that regulate $\mathrm{Mg}^{2+}$ homeostasis in the cells of humans and other vertebrates have remained largely unknown. However, recent developments in understanding the function of two novel ion channels of the TRPM family suggest that these proteins are critical regulators of our body's access to environmental $\mathrm{Mg}^{2+}$ and our body's cell's access to body-fluid $\mathrm{Mg}^{2+}$.

The completion of various model organism genomes along with the human genome has accelerated research in ion channel biology by allowing the identification of many new ion channels by sequence analysis. This strategy has led to a particularly large expansion of the TRP (transient receptor potential) superfamily of ion channels (8), members of which share significant amino acid similarity primarily over TM-spanning regions. Within the TRP superfamily, five subtypes of channels are distinguishable on the basis of conservation of domains outside the TM-spanning regions, and these have now been designated TRPC, TRPV, TRPM, TRPML, and TRP-PKD (see Ref. 8). TRPM (transient receptor potential cation channel superfamily, melastatin subfamily) members are notable for their conserved domain structure, including a cassette of canonical N-terminal, transmembrane-spanning, and coiled coil regions that facilitated the identification of the various human members by sequence alignment (see Fig. $1 A$ ) and for their diverse gating mechanisms and permeation properties (reviewed in Ref. 9).

Two TRPM family members, subsequently designated TRPM6 and TRPM7, drew immediate interest from electrophysiologists and biochemists upon their discovery, as se- 
A

TRPM family core
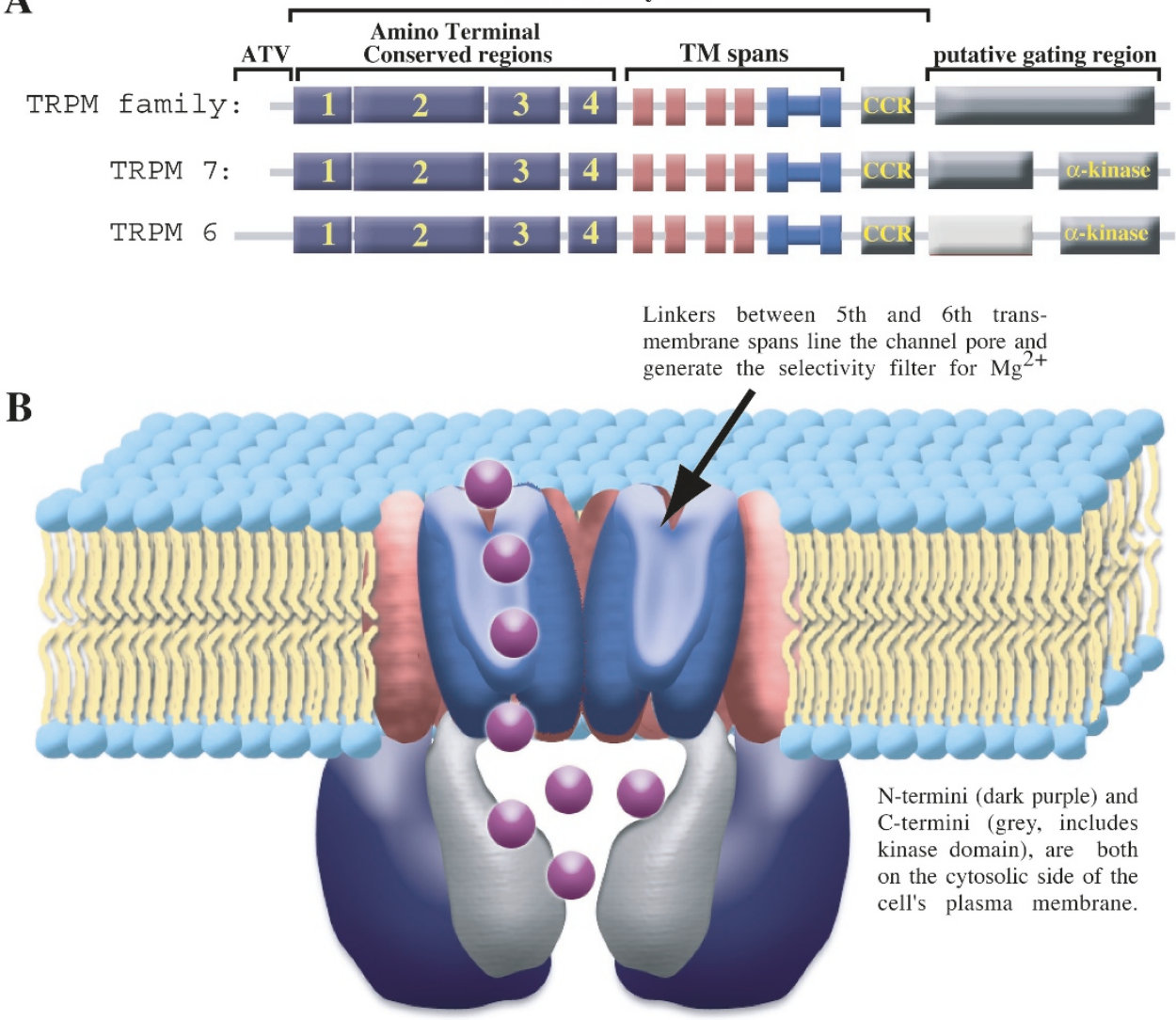

Figure 1. (A) Schematic structure of TRPM family channels TRPM6 and TRPM7, respectively. TRPM6 and TRPM7 are highly homologous except for the region between the TM spans and the $\alpha$-kinase domain. Amino terminal variable region (ATV) is a short region at the N-termini of TRPM channels that is specific to each member. The amino terminal conserved region defines the TRPM family and is composed of four conserved subdomains separated by short linker regions of variable length in different TRPM members. Coiled coil region (CCR) is a region of highly coiled coil character positioned just C-terminal to the sixth TM span in all TRPM members. (B) Model for the three-dimensional organization of TRPM family channels. The model represents a channel transected in half (a single channel is most likely made of four TRPM subunits, all of the same type) and bent slightly open in the plane of the plasma membrane for illustrative purposes. The $\mathrm{N}$ - and $\mathrm{C}$-termini both are intracellular, and they are pictured in red; the fifth and sixth TM spans and linker region, which form the channel pore, are pictured in blue. Dark purple spheres represent permeating $\mathrm{Mg}^{2+}$, which would create a local domain of high free $\left[\mathrm{Mg}^{2+}\right]$ around the cytosolic channel structures upon channel opening. On the basis of the functional analyses available for TRPM2 and TRPM7, the C-terminal regions of TRPM channels seem to be critical for the control of channel gating.

quence analyses suggested that they should function not only as ion channels but also as protein kinases (Fig. 1A), a combination unique among all known proteins. The combined conclusions from several groups' initial analyses of TRPM7 indicated that TRPM7's ion channel domain is capable of permeating some combination of $\mathrm{Ca}^{2+}, \mathrm{Mg}^{2+}$, and/or $\mathrm{Na}^{+}$and that its gating is controlled by intracellular concentrations of $\mathrm{Mg}^{2+}$ or $\mathrm{Mg}^{2+}$ /nucleotide complexes, G-proteins, and turnover of a specific membrane lipid (10-15). Insights into the role of the kinase domain in TRPM7 function were less forthcoming, as the activity of the kinase domain of TRPM7 was initially reported as required for channel gating, yet it did not seem to be involved in channel suppression by several types of manipulations (13-15). A crystal structure for the isolated TRPM7 kinase domain was also determined, providing an important tool for structure/function analyses of the kinase domain's phosphotransferase activity but no further clues to its connection to TRPM7 channel domain function. During the same period, little progress was made in electrophysiologic and biochemical studies of TRPM6, a situation that persists to the present and that is most likely due to difficulties with surface expression and/or lack of constitutive gating of recombinant homomultimeric TRPM6 channels. However, the isolated kinase domain of TRPM6 was expressed and its phosphotransferase activity was characterized (16), with the available data indicating that it has biochemical properties nearly identical to those of the TRPM7 kinase domain.

Although providing important information regarding the molecular properties of TRPM6 and TRPM7, the electrophysiologic and biochemical data described above offered no exceptional insight into the biologic function of these proteins. However, shortly after the initial data on TRPM7's ion channel function were reported, two groups using a candidate gene approach to identify the locus for an autosomal recessive form of hypomagnesemia began to focus on the TRPM6 gene, which mapped into a genomic region shown to contain the disease locus (17). Both groups found one or more mutations likely to inactivate TRPM6 in both alleles of TRPM6 genes from affected patients $(18,19)$. In marked contrast to patients who 
have an alternative form of inherited hypomagnesemia and exhibit defects in paracellular $\mathrm{Mg}^{2+}$ absorption as a result of defects in the tight junction protein Paracellin-1, analyses of the urinary fractional excretion of $\mathrm{Mg}^{2+}$ of patients with this disorder demonstrated that they excrete inappropriately large amounts of $\mathrm{Mg}^{2+}$ as a result of a defect in transcellular $\mathrm{Mg}^{2+}$ uptake in the distal convoluted tubule (19). Consistent with this, analysis of TRPM6 transcripts indicated expression primarily in intestine and kidney within regions previously shown to be involved in active transcellular $\mathrm{Mg}^{2+}$ uptake $(18,19)$. Taking note of these data along with the capacity of $\mathrm{Mg}^{2+}$ supplementation to complement defects in $\mathrm{Mg}^{2+}$ uptake in lower organisms, our laboratory evaluated whether supplemental $\mathrm{Mg}^{2+}$ could similarly complement cultured cells rendered TRPM7 deficient by conditional gene targeting. Remarkably, supplemental $\mathrm{Mg}^{2+}$ provided in amounts $\sim 10$ - to 20 -fold above typical levels in cell culture media allowed TRPM7-deficient cells to grow seemingly normally, and the use of supplemental $\mathrm{Mg}^{2+}$ in subsequent experiments allowed us to generate additional cell lines rendered stably TRPM7 deficient and engineered to express various types of mutant TRPM7 channels (20). Studies using these cell lines subsequently established that TRPM7 deficiency is associated with profound cellular $\mathrm{Mg}^{2+}$ deficiency under standard culture conditions and helped to demonstrate the existence of a functional coupling between TRPM7 channel and kinase domains by showing that expression of TRPM7 channels lacking a kinase domain results in altered $\mathrm{Mg}^{2+}$ homeostasis and growth (20).

What type of biologic roles might be envisioned for TRPM6 and TRPM7 given the accumulated new data? Previous reports indicated that patients with primary hypomagnesemia of the type linked to deficient TRPM6 function are able to live normal lives if they receive oral $\mathrm{Mg}^{2+}$ supplementation sufficient to maintain near-normal serum $\mathrm{Mg}^{2+}$. On this basis, the capacity of $\mathrm{Mg}^{2+}$ supplementation to rescue deficiency of TRPM7 in cultured cells and the high degree of protein sequence homology of TRPM6 and TRPM7, it seems likely that both proteins have roles involving transmembrane uptake of $\mathrm{Mg}^{2+}$. However, these roles seem to be physiologically distinct: the selective expression of TRPM6 within kidney and intestine along with the organismal $\mathrm{Mg}^{2+}$-deficient phenotype of TRPM6deficient humans suggests that TRPM6 regulates $\mathrm{Mg}^{2+}$ uptake from the external environment to the extracellular fluids of an organism; similarly, the ubiquitous expression of TRPM7 and the profound cellular $\mathrm{Mg}^{2+}$ deficiency that occurs in TRPM7deficient cells in culture suggest that it has an analogous role in the regulation of $\mathrm{Mg}^{2+}$ uptake from extracellular fluids to the intracellular milieu of cells. The recent data from our laboratory addressing the relationship between channel and kinase domains of TRPM7 further suggest how the dual channel and kinase domains of these proteins might work together (Fig. $1 B)$ : the channel domain permeates $\mathrm{Mg}^{2+}$ and influences the phosphotransferase activity of the kinase domain either indirectly through the resulting local changes in $\mathrm{Mg}^{2+}$ and/or, alternatively, directly through conformational changes induced by channel gating. Whereas many channels are known to be regulated via phosphorylation by physically associated protein kinases, to our knowledge, a reverse relationship in which ion flow through a channel regulates a closely associated kinase has not been previously described. Because protein kinases act to encode information as a stable biochemical change informative to other components of a cell, the role of the protein kinase domains of TRPM6 and TRPM7 would presumably be to transfer information regarding the channel's gating or cell's $\mathrm{Mg}^{2+}$ status to a (the) downstream molecular or protein targets. Such a mechanism has the important implication that these channels may function both as a $\mathrm{Mg}^{2+}$ uptake mechanism and as a form of $\mathrm{Mg}^{2+}$ sensor.

What are the implications of these new results for cell biologists? Several unresolved issues stand out as critical to a better understanding of TRPM6 and TRPM7 function and their respective roles in vertebrate cell biology. Certainly functional characterization of TRPM6 using a combination of biochemical and patch-clamp approaches is a prerequisite to a better understanding of TRPM6 and TRPM7 structure/function relationships. Another major issue is whether TRPM6 and TRPM7 are themselves major cellular bulk $\mathrm{Mg}^{2+}$ uptake mechanisms or instead function primarily or solely as $\mathrm{Mg}^{2+}$ sensors. Of relevance to the latter possibility is that the existence of a ubiquitous $\mathrm{Mg}^{2+}$ sensor has been proposed on the basis of previous physiologic investigations of $\mathrm{Mg}^{2+}$ metabolism (2123 ), although these studies did not provide insight into what the connection between the proposed sensing mechanism and $\mathrm{Mg}^{2+}$ uptake and efflux mechanisms might be. Whether TRPM6 or TRPM7 represents the sensing mechanism reported in those studies is not yet known, but this is clearly an area of interest for future work. A related aspect of this issue is the identities of direct substrates, pathways, and genes that are targets of TRPM7 phosphotransferase activity. An obvious set of potential downstream targets of information from the TRPM6/7 kinases would be $\mathrm{Mg}^{2+}$ efflux transporters, on the basis of the simple rationale that it would be advantageous to a cell to coordinate $\mathrm{Mg}^{2+}$ uptake and efflux so as to ensure that efflux occurs only under conditions when $\mathrm{Mg}^{2+}$ is available in sufficient amounts extracellularly. If this is the case, then identification of TRPM6 and TRPM7 may facilitate the identification and functional characterization of these proteins. Finally, TRPM7 function has been reported to be rapidly inhibited by G-proteins and phosphoinositide turnover $(12,15)$, suggesting that regulation of $\mathrm{Mg}^{2+}$ fluxes via alteration of TRPM7-mediated $\mathrm{Mg}^{2+}$ entry might be occurring during diverse types of signaling events. What purpose(s) this might serve is (are) presently unclear, but alterations of subplasmalemmal $\mathrm{Mg}^{2+}$ could potentially affect any process involving the action of enzymes that require $\mathrm{Mg}^{2+}$ for activity (including, e.g. many types of protein kinases), processes involving $\mathrm{Mg}^{2+}$ binding lipids $\left(\mathrm{Mg}^{2+}\right.$ binds a variety of negatively charged lipid moieties), mitochondrial ATP production $\left(\mathrm{Mg}^{2+}\right.$ is an important internal mitochondrial cation, and substantial $\mathrm{Mg}^{2+}$ is complexed with ATP), and the actions of ion channels whose gating is $\mathrm{Mg}^{2+}$ regulated (reviewed in Refs. 1 and 2). Future work will no doubt begin to clarify each of the above issues and enhance our understanding of how these novel proteins function in vertebrate cell biology. 
Note Added in Proof. A recent electrophysiologic characterization of TRPM6 suggests that it behaves quite similarly to TRPM7 in terms of capacity to permeate $\mathrm{Mg}^{2+}$ and regulation by $\mathrm{Mg}^{2+}$, consistent with its also serving as a $\mathrm{Mg}^{2+}$ uptake channel (24).

Acknowledgments. We are grateful to Jean-Pierre Kinet, Tomohiro Kurosaki, and Reinhold Penner for insightful discussions.

\section{REFERENCES}

1. Romani AM, Scarpa A 2000 Regulation of cellular magnesium. Front Biosci 5:D720-D734

2. Saris NE, Mervaala E, Karppanen H, Khawaja JA, Lewenstam A 2000 Magnesium. An update on physiological, clinical and analytical aspects. Clin Chim Acta 294:1-26

3. Maguire ME $1992 \mathrm{MgtA}$ and MgtB: prokaryotic P-type ATPases that mediate Mg2+ influx. J Bioenerg Biomembr 24:319-328

4. Kehres DG, Lawyer CH, Maguire ME 1998 The CorA magnesium transporter gene family. Microb Comp Genomics 3:151-169

5. Smith RL, Maguire ME 1998 Microbial magnesium transport: unusual transporters searching for identity. Mol Microbiol 28:217-226

6. Graschopf A, Stadler JA, Hoellerer MK, Eder S, Sieghardt M, Kohlwein SD, Schweyen RJ 2001 The yeast plasma membrane protein Alr1 controls Mg2+ homeostasis and is subject to $\mathrm{Mg} 2+$-dependent control of its synthesis and degradation. J Biol Chem 276:16216-16222

7. Zsurka G, Gregan J, Schweyen RJ 2001 The human mitochondrial Mrs2 protein functionally substitutes for its yeast homologue, a candidate magnesium transporter. Genomics 72:158-168

8. Montell C, Birnbaumer L, Flockerzi V, Bindels RJ, Bruford EA, Caterina MJ, Clapham DE, Harteneck C, Heller S, Julius D, Kojima I, Mori Y, Penner R, Prawitt D, Scharenberg AM, Schultz G, Shimizu N, Zhu MX 2002 A unified nomenclature for the superfamily of TRP cation channels. Mol Cell 9:229-231

9. Clapham DE, Runnels LW, Strubing C 2001 The TRP ion channel family Nat Rev Neurosci 2:387-396

10. Kozak JA, Kerschbaum HH, Cahalan MD 2002 Distinct properties of CRAC and MIC channels in RBL cells. J Gen Physiol 120:221-235
11. Prakriya M, Lewis RS 2002 Separation and characterization of currents through store-operated CRAC channels and $\operatorname{Mg}(2+)$-inhibited cation (MIC) channels. J Gen Physiol 119:487-507

12. Hermosura MC, Monteilh-Zoller MK, Scharenberg AM, Penner R, Fleig A 2002 Dissociation of the store-operated calcium current I(CRAC) and the Mg-nucleotideregulated metal ion current MagNuM. J Physiol 539:445-458

13. Nadler MJ, Hermosura MC, Inabe K, Perraud AL, Zhu Q, Stokes AJ, Kurosaki T, Kinet JP, Penner R, Scharenberg AM, Fleig A 2001 LTRPC7 is a Mg ATP-regulated divalent cation channel required for cell viability. Nature 411:590-595

14. Runnels LW, Yue L, Clapham DE 2001 TRP-PLIK, a bifunctional protein with kinase and ion channel activities. Science 291:1043-1047

15. Runnels LW, Yue L, Clapham DE 2002 The TRPM7 channel is inactivated by PIP(2) hydrolysis. Nat Cell Biol 4:329-336

16. Ryazanova LV, Pavur KS, Petrov AN, Dorovkov MV, Ryazanov AG 2001 Novel type of signaling molecules: protein kinases covalently linked to ion channels. Mol Biol (Moscow) 35:321-332

17. Walder RY, Shalev H, Brennan TM, Carmi R, Elbedour K, Scott DA, Hanauer A, Mark AL, Patil S, Stone EM, Sheffield VC 1997 Familial hypomagnesemia maps to chromosome 9q, not to the $\mathrm{X}$ chromosome: genetic linkage mapping and analysis of a balanced translocation breakpoint. Hum Mol Genet 6:1491-1497

18. Schlingmann KP, Weber S, Peters M, Niemann Nejsum L, Vitzthum H, Klingel K, Kratz M, Haddad E, Ristoff E, Dinour D, Syrrou M, Nielsen S, Sassen M, Waldegger S, Seyberth HW, Konrad M 2002 Hypomagnesemia with secondary hypocalcemia is caused by mutations in TRPM6, a new member of the TRPM gene family. Nat Genet $31: 166-170$

19. Walder RY, Landau D, Meyer P, Shalev H, Tsolia M, Borochowitz Z, Boettger MB, Beck GE, Englehardt RK, Carmi R, Sheffield VC 2002 Mutation of TRPM6 causes familial hypomagnesemia with secondary hypocalcemia. Nat Genet 31:171-174

20. Schmitz C, Perraud A-L, Johnson CO, Inabe K, Smith MK, Penner R, Kurosaki T, Fleig A, Scharenberg AM 2003 Regulation of vertebrate cellular $\mathrm{Mg}^{2+}$ homeostasis by TRPM7. Cell 114:191-200

21. Quamme GA, Dai LJ 1990 Presence of a novel influx pathway for Mg2 + in MDCK cells. Am J Physiol 259:C521-C525

22. Quamme GA, Rabkin SW 1990 Cytosolic free magnesium in cardiac myocytes: identification of a Mg2 + influx pathway. Biochem Biophys Res Commun 167:14061412

23. Dai LJ, Quamme GA 1991 Intracellular Mg2+ and magnesium depletion in isolated renal thick ascending limb cells. J Clin Invest 88:1255-1264

24. Voets J, Nilius B, Hoefs S, van der Kemp AW, Droogmans G, Bindels RJ, Hoenderop JG 2004 TRPM6 forms the channel involved in intestinal and renal Mg2 + absorption. J Biol Chem. 279:19-25 